\title{
Fictionality and Imagination, Revisited
}

I present and discuss a counterexample to Kendall Walton's necessary condition for fictionality that arises from considering serial fictions. I argue that although Walton's has not in fact provided a necessary condition for fictionality, a more complex version of Walton's condition is immune from the counterexample.

\section{Introduction}

In Mimesis as Make Believe (1990: 39, 60-61), Kendall Walton proposed a reductive account of fictionality that he later stated explicitly as

1. A proposition is fictional in (the world of) a particular work, $W$, just in case appreciators of that work are to imagine it, just in case full appreciation of $W$ requires imagining it (Walton 2015: 19). ${ }^{1}$

In his 2015, Walton presents and endorses a series of putative counterexamples to (1). Walton's $(2015: 17,19)$ new view is that (1) provides a necessary but not sufficient condition for fictionality. What I want to focus on in this paper is counterexamples to (1) from misleading stories such as the following:

\footnotetext{
${ }^{1}$ Following Walton, I'll talk as if there are propositions in play here, but many who take fictional names to be empty would reject this. Below I suppress Walton's gloss on 'appreciators of that work are to imagine it' as 'full appreciation of $W$ requires imagining it'.
} 
Background music in film can easily create an illusion, give the impression that a certain proposition is fictional which turns out not to be. A murder mystery may trick readers into thinking that the butler is the villain and to imagine that he is, though they discover in the end that, say, the UPS deliveryman, not the butler, committed the crime (Walton 2015: 24).

Discussing the above counterexample, Walton writes that

We are expected to imagine, on reading Chapter 3, that the butler did the dastardly deed, but by the end of the novel, when all is said and done, we realize that we are to imagine not this, but that it is the UPS delivery man who is guilty. The suggestion is that only what is to be imagined at the end, after we have experienced and absorbed all relevant aspects of the work, is fictional in the work (Walton 2015: 26).

In order to account for the above counterexample to (1), we can amend (1) as follows:

2. A proposition is fictional in (the world of) a particular work, $W$, just in case appreciators of that work are to imagine it once they have absorbed all relevant aspects of the work.

Walton himself rejects (2) because he thinks that it does not provide a sufficient condition for fictionality given the further putative counterexamples that he provides. It is, however, controversial whether Walton's further examples do provide counterexamples to (1) and (2). Richard Woodward (2014, forthcoming), for example, has recently argued that many of 
Walton's cases are not genuine counterexamples. But even if Walton has in fact furnished further counterexamples to (1) that (2) does not address, this does not in itself tell against (2) as a response to Walton's misleading story counterexamples to (1). For why should "we expect all counterexamples to have a uniform solution, given the multifaceted nature of representational art" (Woodward, 2014: 832)? In any case, my concern in this paper is with misleading stories of the sort Walton adduces above and so other types of counterexample to (2) can be ignored for present purposes.

In $\S 2$ I present and discuss a further counterexample from misleading stories to both the necessity and sufficiency directions of (1) and (2). So, regardless of whether there are other counterexamples to (1) and (2), (2) is not a general solution to (1)'s failure to provide a sufficient condition for fictionality in the face of misleading stories. Moreover, my counterexample shows that Walton was wrong to claim that (1) provides a necessary condition for fictionality. I then (§3) propose an account of fiction, Waltonian in spirit, that is immune to the sorts of counterexamples from misleading fictions discussed here. Whether this account provides a sufficient condition for fictionality in general depends, in part, on whether Walton's other putative counterexamples to (1) genuinely are counterexamples. But this is not a question considered here.

\section{Counterexamples from Serial Fiction}

The above formulations of fictionality, (1) and (2), presume that each work concerns a single fictional world. And in his initial discussion, Walton (1990: 58) assumes for simplicity that each work concerns a single fictional world and that each fictional world is the subject of a single work. Here I want to bracket failures of this assumption arising from multiple interpretations of a work, and from narrators not inhabiting the primary fictional world of the 
work, since these failures do not bear on our discussion. ${ }^{2}$ I do, however, want to discuss how serial fictions, such as the Star Wars films, which seem to show that multiple works can concern the same world, show the falsity of both directions of (1) and (2).

Here are the putative counterexamples to (1) and (2)

Sufficiency: In watching and after the end of the first of the Star Wars films, Episode IV: A New Hope (henceforth Hope), we are to imagine that Vader is not Luke's father. Nevertheless, it is not the case that Vader is not Luke's father in (the world of) Hope. If this is correct, then neither (1) nor (2) provide a sufficient condition for fictionality.

Necessity: In watching Hope, we are not at any stage invited to imagine that Darth Vader is Luke Skywalker's father. Nevertheless, Vader is Luke's father in (the world of) Hope. If this is correct, then neither (1) nor (2) provide a necessary condition for fictionality.

Sufficiency is simply a serial fiction version of Walton's counterexample to the sufficiency of (1). But it also provides a counterexample to (2), since what one is to imagine at the end of the work Hope, an instalment of a serial fiction, is not sufficient for what is true in that instalment. One could reject Sufficiency by accepting that although Hope does not invite us to imagine that Vader is Luke's father, neither does it invite us to imagine that Vader is not Luke's father. Rather, the film leaves the matter open. But Walton is explicit that what is important for the fictionality of $\mathrm{P}$ is that we are imagine $\mathrm{P}$, should the question arise, should

\footnotetext{
${ }^{2}$ For a discussion of multiple worlds for a single work see Walton (1990: 58, 285-287, §9.6; and 2015: 31-34)
} 
we be forced to choose between imagining $P$ and imaging not-P. ${ }^{3}$ So specified, it is clear that we are to imagine that Vader is not Luke's father rather than Vader is Luke's father.

Still, one might object to Sufficiency along the following lines. It is not true according to Hope that Vader is Luke's father and so there is no counterexample to (2). But whilst I accept the premise, the conclusion does not follow since (2) is not formulated in terms of what is true according to the fiction, rather it concerns what is fictional or true in (the world of) the fiction. What the above examples show is that what is true in the world of the fiction can come apart from what is true according to the fiction. It is because of this that earlier episodes or chapters can be misleading. So although it is not true according to Hope that Vader is Luke's father, this does not impugn Sufficiency. ${ }^{4}$

In any case, all we need is a single example that does satisfy the above structure to cause problems for (2). So, we could take Walton's own case of the crime fiction above, and simply adapt it to a case of serial fiction - let's make each chapter an instalment of a serial fiction. In such a case, although the earlier instalment invites us to imagine that the butler did it, it is not true in the world of that fiction (just as it is not true in the world of the early chapters of Walton's hypothetical novel) that the butler did it. If Walton's case above is a counterexample to (1), then Sufficiency is a counterexample to (2).

The putative counterexample provided by Necessity is more involved. The idea behind Necessity, is that

\footnotetext{
${ }^{3}$ See Walton (1990: 39-41, 57-61) for this qualification of fictionality.

${ }^{4}$ See Sainsbury (2014) and Walters (2015) for discussions of different sorts of fiction operators.
} 


\section{Vader is Luke's father}

is true in (the world of) Hope in virtue of what happens in later instalments of the Star Wars movies. In particular, given that it is revealed in The Empire Strikes Back (henceforth Empire) that (3) is true in (the world of) Empire, I claim that (3) is true in (the world of) Hope. We can regiment the thinking behind Necessity in the following argument:
A. Vader is Luke's father in (the world of) Empire
B. The world of Empire is (identical to) the world of Hope
C. Therefore, Vader is Luke's father in (the world of) Hope
D. Proper engagement with Hope (alone) does not, at any stage, require one to imagine that Vader is Luke's father.
E. Hope (alone) is a work.
F. Therefore, there is a work, $W$, such that there is some proposition, $\mathrm{P}$, true in $\mathrm{W}$, but proper engagement with $W$ does not require one to imagine $\mathrm{P}$, at any stage.

The argument is valid, so if Necessity does not provide a genuine counterexample to (1) and (2), one of the premises (A), (B), (D), and (E) must be rejected. Let's consider the options. ${ }^{5}$

First, we could deny (E) - that Hope itself is a work - by claiming that individual instalments of serial fictions are not themselves works. Whilst this might save the letter of (2), it would not be enough to save its spirit. For as Walton (1990: 58) writes, "we may sometimes want to say that certain ... parts of works (ones that are not works themselves) have their own

\footnotetext{
${ }^{5}$ Some of this discussion pertains to Sufficiency as well, but above I was content to claim that if Walton has provided a counterexample to (1) above, then Sufficiency, by analogy, represents a counterexample to (2).
} 
fictional worlds". If so, then dropping (E) does not impugn the case against (3) being true in (the world of) Hope, even though there is no prescription to imagine it. As such the generalization of (2) to cover parts of works does not provide a necessary condition on fictionality unless some other premise of the argument above is false. Moreover, Walton's own non-serial fiction case above would provide an example of this: it is true in the world of Chapter 3, that the UPS deliveryman did it, even though there is no prescription to imagine this.

In any case, the claim that instalments of serial fictions, such as Hope, are not themselves works is radically revisionary. If Hope, or to change the example, The Hobbit, is not a work of fiction, then I don't think that we have an adequate grasp on the notion of a work of fiction. So rejecting $(\mathrm{E})$ is not an option, I think.

A second response, would be to deny (B) - that the world of Empire is the world of Hope and claim that the worlds of instalments of serial fictions are not identical. There are two ways of spelling-out this claim. First, one could deny that the worlds of Hope and of Empire overlap. This response seems to me to lack any plausibility. As McGonigal notes in his discussion of serial fiction, it is part of our understanding of serial fictions that they are fictions comprised of distinct works whose production and reception are via "relevantly discontinuous episodes or instalments" and are "construable as taking place within a single fictional world" (McGonigal 2013:165). If the relevant instalments did not concern at least overlapping worlds, then they would not be serial fictions. At best, they would be fictions that shared the same characters, but not ones that stood in the prequel/sequel relation to one another. 
An alternative way of denying (B), however, would be to say that whilst the worlds of Hope and Empire overlap, they are not identical. In particular, one might think that the world of Hope is only an initial temporal segment of the world of Empire. I don't think this response is correct since it still seems to be a revision of our practice as is brought out by McGonigal's characterization of serial fictions above. However, we should note that if (B) is correct and the worlds of Hope and Empire are identical, then we can pull apart what is true in the world of a work and what is true in the work. For instance, assuming that Hope and Empire concern the same world,

4. In the world of Hope (aka the world of Empire), Luke visits Yoda on Dagobah

is true, whereas

5. In Hope, Luke visits Yoda on Dagobah

is, it seems, false, since Luke doesn't visit Yoda until the events depicted in Empire. What 'in Hope' apparently does is restrict attention to the temporal segment of the world of Hope (aka the world of Empire) that Hope itself is concerned with.

If this is right, then we can pick apart two readings of (1) and (2), one concerning what is true in a work, and one concerning what is true in the world of a work. (4), I claim provides a counterexample to the left-to-right direction of the latter reading of (1) and (2), whereas (5) is not a counterexample to the former reading. Of course, one may instead take this to show that (B) is in fact false. 
Returning to the main argument for Necessity, let us grant for the sake of argument that (B) is false and that the world of Hope is only a proper part of the world of Empire. This is sufficient to block the argument for Necessity (the claim that in (the world of) Hope, Vader is Luke's father, but that we are not required to imagine this) as stated, but it does not really get to the heart of the matter. This is because (B) is stronger than is needed to support Necessity. The argument remains valid if we replace (B) with

G. If Vader is Luke's father in (the world of) Empire, then Vader is Luke's father in (the world of) Hope.

As we saw with (5) above, we do not accept the generalized version of $(\mathrm{G})$,

H. If $\mathrm{P}$ is true in (the world of) Empire, then $\mathrm{P}$ is true in (the world of) Hope,

because although Luke visits Dagobah in (the world of) Empire, it is not the case that he visits Dagobah in Hope, and nor, assuming that the world of Hope is only a proper part of the world of Empire, does he visit Dagobah in the world of Hope.

There is, however, a key difference between

\section{Vader is Luke's father}

and the claim that Luke visits Dagobah, in that whilst it can be the case that Luke visits Dagobah in the events depicted by Empire, but not by Hope, it cannot (in the relevant sense) be the case that Vader is Luke's father in the events depicted by Empire, but not in the events 
depicted by Hope. Or to put things another way, if Vader is Luke's father in the world of Empire, he is also Vader's father in the world of Hope. Why? Because, at least in (the worlds of) fictions like the Star Wars films, if $\mathrm{x}$ is the father of $\mathrm{y}$ at $\mathrm{t}$, then $\mathrm{x}$ is the father of $\mathrm{y}$ at every earlier time at which both $\mathrm{x}$ and $\mathrm{y}$ exist. But the analogous principle about visiting fails, since $\mathrm{x}$ can visit $\mathrm{y}$ at $\mathrm{t}$ and not visit $\mathrm{y}$ at some earlier time. So even if the world of Hope is only a proper part of the world of Empire, and even if what is true in Hope is not identical to what is true in Empire, it is still the case that (G) holds, and so the argument for Necessity goes through.

The next response to the argument concedes that although

(3) Vader is Luke's father

is true in (the world of) Hope, proper engagement with Hope alone requires the audience to imagine (3). That is, it denies (D). Part of the point of serial fictions, however, is that they unfold over time, inviting us to imagine new things at later times. But this point is lost if we claim that Hope alone prescribes the imagination of (3). Moreover, serial fictions are sometimes devised expressly to mislead the reader with earlier instalments, just as early chapters of murder mysteries are designed to mislead us into thinking that the Butler, not the UPS deliveryman did it. Walton, it seems, agrees since of his own counterexample to (1) he writes that "[w]e are expected to imagine, on reading Chapter 3, that the butler did the dastardly deed" (2015: 26). And what holds for the early chapters of novels, holds for the early instalments of serial fictions. Again, the present response cannot account for this. 
Moreover, since it should be conceded that appreciation of Hope does, or at least could, prescribe imagining Vader is not Luke's father, at least if the question arises, then the present response prescribes both imagining that Vader is not Luke's father and imagining that Vader is Luke's father. But serial fictions do not as a matter of course make these types of demands.

Finally, the present response appears to have the implausible consequence that proper engagement with Hope in 1977 required imagining that Vader was Luke's father, despite there being nothing to suggest this in the film and no way, we may suppose, that a viewer could have known of the events of Empire. Any theory that embraces this consequence seems to make our proper appreciation of fiction too onerous. One might try to deny that this is a consequence of denying (D), however, by claiming that although proper engagement with Hope now requires imagining (3), proper engagement in 1977 did not. But if this is not to concede that Necessity provides a counterexample to (2), then this must be accompanied by the claim that although (3) is now true in (the world of) Hope, it was not true in 1977 in (the world of) Hope.

I think this strategy is only plausible if the Star Wars series were unplanned to the extent that George Lucas had not, in 1977, decided upon the relevant aspects of the plot of Empire. If by the release of Hope, Empire had already been plotted in the relevant respects, then it seems that (3) was already a correct, albeit it odd thing to say in 1977. And, as Kripke (2013: 57) notes, an utterance of a sentence like (3) is correct iff it is true in the (world of the) relevant fiction. ${ }^{6}$ Given that in 1977 Empire had yet to be released, Hope appears to be the relevant

\footnotetext{
${ }^{6}$ Actually, Kripke is not careful to distinguish between the operators 'in the fiction' and 'according to the fiction'. See my 2015 for some discussion of the two operators, the differences between them, and why the correctness of (3) is tied to the truth of 'in Star Wars, Vader is Luke's father'.
} 
fiction for assessing the correctness of utterances of (3) in 1977, and so if the utterance is correct, then (3) is true in (the world of) Hope. This mirrors Walton's verdict in the case of the misleading early chapters of the murder mystery counterexample to the sufficiency of (1) given above. That is, upon having read Chapter 3, although it would be an odd thing to say that the UPS man did it, it would in fact be correct to say this, in virtue of the later chapters.

Moreover, as I have argued elsewhere (Walters, 2015), even if the Star Wars series had been unplanned, I think that (3) would still have been true in (the world of) Hope in $1977 .{ }^{7}$ This is because although an utterance of (3) in 1977 would have struck us as incorrect, our retrospective assessment of that utterance in 1980 after the release of Empire would have counted it as correct. This combined with the claim that an utterance of (3) in 1977 is correct iff (3) is true in 1977 in (the world of) Hope, gives us that (3) was in fact true in the world of Hope in 1977. Compare our retrospective assessment today of an utterance in 1945 of 'the DNA of familial relations are similar in predictable ways' or of 'Regan will win the 1980 US Presidential election'. These utterances count as correct because what they claimed was true at the time of utterance, even though no one could have known they were true in 1945.

The final response to the argument for Necessity is to deny (A) and claim that it is not true in (the world of) Empire that Vader is Luke's father. By my own lights, it could turn out that future sequels reveal that Vader is not in fact Luke's father, in which case (A) would indeed be false. But if this were to be the case, then the fact that we are not to imagine that Vader is not Luke's father in Empire would itself provide a counterexample to the left-to-right direction of (2). So regardless of the truth of (A), a counterexample to (1) and (2) along the lines of Necessity can be constructed.

\footnotetext{
${ }^{7}$ Although see McGonigal (2013) and Caplan (2014) for a different take on this issue.
} 
This, then, completes the defence of my argument that Necessity provides a counterexample to the left-to-right direction of (1) and (2).

\section{Amending Walton's Account}

Given that truth in fiction comes apart from prescriptions to imagine, one might take this as a reason to abandon Walton's approach entirely. My aim here is not to defend a Waltonian approach in full generality, but rather to discuss its prospects for dealing with misleading stories. So can Walton's approach be amended to deal with the above counterexamples?

The above counterexamples to (1) and (2) are similar to Walton's counterexample from the introduction, but whereas his regards the unfolding of the events of a fictional world within a single work, mine concerns such events unfolding across multiple works. As such, we might expect a Waltonian to approach these counterexamples in similar ways. In the face of the misleading intrafictional counterexample to (1), we amended (1) by limiting the relevant imaginings to those ascribed at the end of reading the work. This suggests that we respond to my interfictional counterexamples to (2) along the same lines:

6. A proposition is fictional in (the world of) a particular work, $W$, iff appreciators of the maximal fiction of which $W$ is a part are to imagine it. ${ }^{8}$

(6) is not satisfactory as it stands, however, since it assumes that a given work is part of single maximal fiction. But this assumption can fail. First, a work will not be part of a single

\footnotetext{
${ }^{8}$ For some purposes, at least, we may want to restrict (6) to the canonical/non-canonical episodes of the serial fiction of which $W$ is a part. I ignore such restrictions below.
} 
maximal fiction when it has two sequels neither of which are sequels of the other. ${ }^{9}$ For example, both Kevin J. Anderson's Jedi Academy trilogy and Timothy Zahn's Thrawn trilogy, are sequels to Star Wars Episode VI: Return of the Jedi by James Kahn, but are parallel developments of the Star Wars universe with neither being sequels of the other. To deal with such branching serial fictions we need distinguish multiple divergent worlds of a work, with the initial instalments concerning multiple worlds and the later branching sequels concerning only a proper subset of these. We could then drop talk of the world of a work in favour of $a$ world of a work, giving:

7. A proposition is fictional in a world of a particular work, $W$, iff appreciators of some maximal fiction of which $W$ is a part are to imagine it.

Alternatively, we could relativize fictionality to worlds of a work:

8. A proposition is fictional in world $A$ of a particular work, $W$, iff appreciators of the maximal fiction that concerns $A$, of which $W$ is a part, are to imagine it.

Second, a fictional episode need not be part of a single maximal fiction. It could be that for each fictional episode in a series there is a later one. There are two cases to consider:

i. It is not the case that from some point onwards we are to imagine P.

ii. It is the case that from some point onwards we are to imagine P.

\footnotetext{
${ }^{9}$ A similar point could be made about prequels.
} 
In type (i) cases, (6) is not threatened since it is plausible that in such cases $\mathrm{P}$ is not fictional in the world of the fiction. This is explained in Walton's framework in terms of the fact that there is not at any point a stable prescription to imagine $\mathrm{P}$.

But what of type (ii) cases? Here it seems that $\mathrm{P}$ is true in the world of the fiction in virtue of there being a stable prescription to imagine $\mathrm{P}$ from some point, despite the lack of a maximal fiction. As a result, we must amend (6) as follows:

9. A proposition, $P$, is fictional in the world of a particular work, $W$, iff there is some fiction $F$, of which $W$ is a part, such that appreciators of $F$ are to imagine $P$; and for any fiction $F^{*}$, of which $W$ is a part, such that appreciators of $F^{*}$ are not to imagine $P$, then $F^{*}$ is a proper part of $F$.

Third, the above two scenarios can be combined to yield branching serial fictions such that for each instalment on some branch, there is a later instalment on that branch. Taking (8) as the proper treatment of branching serial fictions, this suggests the following account of fictionality:

10. A proposition, $P$, is fictional the world $A$ of a particular work, $W$, iff there is some fiction $F$ that concerns $A$, of which $W$ is a part, such that appreciators of $F$ are to imagine $P$; and for any fiction $F^{*}$ that concerns $A$, of which $W$ is a part, such that appreciators of $F^{*}$ are not to imagine $P$, then $F^{*}$ is a proper part of $F$.

One might, however, think that any account of fictionality along the lines of (10) is doomed to failure, since there are many more things true in a fiction than we are to imagine - the truth 
of Goldbach's conjecture (or its negation), for example. Granting that such background truths are in fact true in the relevant fictions, Waltonians have two options. First, they could claim that we are in fact invited to imagine them. Second, she could modify her account of fictionality to allow that propositions could be made fictional by principles of generation as well as by prescriptions to imagine. Given that it would be some such principle of generation that would lead to a prescription to imagine, both options rest on whether there is a principle of generation that will generate these background fictional truths?

Walton seeks to generate these background truths by appeal to the Reality Principle: "The basic strategy which the Reality Principle attempts to codify is that of making fictional worlds as much like the real one as the core of primary fictional truths permits" (Walton, 1990: 144-145). Walton (145) provides "a working formulation of the Reality Principle" as follows:

Reality Principle: If $\mathrm{p}_{1}, \ldots, \mathrm{p}_{\mathrm{n}}$ are the propositions whose fictionality a representation generates directly, another proposition, $\mathrm{q}$, is fictional in it if, and only if, were it the case that $\mathrm{p}_{1}, \ldots, \mathrm{p}_{\mathrm{n}}$, it would be the case that $\mathrm{q}$.

The Reality Principle, or a variant of it, thus generates the background fictional truths for Walton, whether or not we take this principle to also be generating prescriptions to imagine.

But given our discussion of serial fictions, we can see that the Reality Principle itself needs to be revised. Let us say that propositions true in world A of work $\mathrm{W}$ in virtue of (1) are 'directly true in world A of W. We should then think of a principle of generating background truths along the following lines: 
Reality Principle*: If $\mathrm{p}_{1}, \ldots, \mathrm{p}_{\mathrm{n}}$ are the propositions directly true in world $\mathrm{A}$ of $\mathrm{W}$, another proposition, $\mathrm{q}$, is fictional in $\mathrm{A}$ of $\mathrm{W}$ if, and only if, were it the case that $\mathrm{p}_{1}$, $\ldots, \mathrm{p}_{\mathrm{n}}$, it would be the case that $\mathrm{q}$.

Given something like Reality Principle*, background truths pose no threat to the account of fictionality given here.

\section{Conclusion}

We have seen that serial fictions provide plausible counterexamples to both the necessity and sufficiency of (1) and (2), and so Walton's claim that (1) provides a necessary condition for fictionality is incorrect. Nevertheless, it is, it seems, possible to provide an account of fictionality along the lines of (10) that vindicates Walton's (2015: 17) thought that "Prescriptions to imagine are necessary ... for fictionality". It is just that this condition is not as simple as Walton envisaged. So what is true in (the world of the) fiction, like what is true in reality, is not transparent in any obvious sense. Whether (10) does in fact provide a sufficient condition for fictionality rests, in part, on whether Walton's (2015) other putative counterexamples to the sufficiency of (1)/(2) are genuine..$^{10}$

\section{References}

Caplan, B. 2014: Serial Fiction, Continued. British Journal of Aesthetics 54: 65-76.

\footnotetext{
10 This paper arose from an informative conversation with Nils Stear about my 2015, so many thanks to Nils. Thanks also to two referees and an editor of JAAC for helpful comments. I'd also like to thank the Central European University's Institute of Advanced Study for a fellowship which allowed me to finish this paper.
} 
Kripke, S. 2013: Reference and Existence. Oxford: OUP.

McGonigal, A. 2013: Truth, Relativism and Serial Fiction. British Journal of Aesthetics 53: 165-179.

Sainsbury, R.M. 2014: Fictional Worlds and fiction operators. In M. Garcia-Carpíntero and G. Martí (eds) 2014: Empty Representations: Reference and Non-Existence. Oxford: OUP, pp. 277-289.

Walton, K. 1990: Mimesis as Make-Believe: on the Foundations of the Representational Arts. Cambridge, MA: Harvard University Press.

Walters, L. 2015: Serial Fiction, The End? British Journal of Aesthetics 55: 323-341.

Walton, K. 2015: Fictionality and Imagination - Mind the Gap in his In Other Shoes: Music, Metaphor, Empathy, Existence. Oxford: OUP.

Woodward, R. 2014: Walton on Fictionality. Philosophy Compass 9: 825-836.

Woodward, R. Forthcoming: Fictionality and Photography. Journal of Aesthetics and Art Criticism. 